\title{
VOCABULÁRIO DA LÍNGUA BRASILEIRA DE SINAIS: CONTRIBUIÇÕES NO CONTEXTO NUTRICIONAL
}

\author{
BRAZILIAN SIGN LANGUAGE VOCABULARY: CONTRIBUTIONS IN THE \\ NUTRITIONAL CONTEXT
}

\begin{abstract}
VOCABULARIO DE LA LENGUA BRASILEÑA DE SEÑALES: CONTRIBUCIONES EN EL CONTEXTO NUTRICIONAL
\end{abstract}

Vilma Rodrigues Cardoso*

\section{Resumo}

A ausência de sinais em áreas específicas traz alguns problemas para usuários e profissionais que atuam com a Língua Brasileira de Sinais (Libras). O uso excessivo da datilologia, interrupções na tradução/interpretação e inadequação de significados são alguns desses problemas. Este artigo é resultado de um projeto que teve o objetivo de preparar um glossário para a área da Nutrição, elaborando sinais para os termos: Carboidrato, Fibra, Metabolismo e Proteína, com a participação de uma docente surda e alunas do Curso de Letras: Tradução e Interpretação em Libras/Português, da Universidade Federal de Goiás (UFG), Goiânia. O objetivo deste artigo é descrever a pesquisa, relatando as razões dessa iniciativa, as etapas para alcançar o objetivo proposto e as falhas ocorridas, além da validação e do uso atual desses sinais.

Palavras chave: Criação de sinais. LSB. Neologismo. Nutrição. Terminologia.

\section{Introdução}

Durante a tradução/interpretação do português para a Libras, os profissionais tradutores e intérpretes da língua de sinais/português (TILSP) se deparam com palavras que não têm sinal específico nas diferentes áreas das Ciências Humanas, Exatas e Biológicas. Como recurso auxiliar, os TISLP dispõem de um empréstimo linguístico da língua portuguesa, que é chamado de datilologia ou soletração. Este recurso demanda a realização manual de cada letra da palavra, com base no alfabeto escrito e oral. Embora a comunicação

\footnotetext{
* Mestre em Estudos da Tradução pela Universidade de Brasília (UnB). Intérprete de Libras/Português- UFG. Email: tilsvilma@gmail.com
} 
na Libras se defina pela realização plena dos sinais em sua contextualização e não unicamente pela soletração, na ausência de sinais esse é um recurso auxiliar.

$\mathrm{O}$ uso da datilologia ocorre mais frequentemente em áreas específicas carentes de sinais, como é o caso da Nutrição. Em sua maioria, os surdos têm dificuldades em compreender a palavra soletrada. Essa compreensão depende de seu nível de aprendizado da língua portuguesa. Por conseguinte, a datilologia só traz correspondência direta com o significado da palavra se o surdo estiver familiarizado com esses significados. Muitas vezes, a solução encontrada pelos usuários da Libras é a criação momentânea de sinais, conhecidos como "sinais combinados", para que a tradução e interpretação possam ter melhor fluidez. Nesses casos, o conceito é transmitido pelo TILSP, ou por um especialista da área, e o surdo cria o sinal-termo. A expressão "sinal-termo", utilizada neste trabalho, foi criada por Enilde Faulstich para designar dois conceitos expressivos: o de sinal e o de termo. Essa expressão, de acordo com Faulstich (2014), pode representar conceitos de linguagem especializada, além de também denotar conceitos de palavras simples, compostas, símbolos e fórmulas. Essa expressão, adaptada do português, é usada para representar conceitos de áreas específicas, no que concerne às línguas de sinais.

No processo de criação de sinais, deve-se dar atenção aos métodos empregados, verificando se o surdo compreendeu satisfatoriamente o termo. É possível encontrar vários sinais para uma mesma palavra, os quais não descrevem o termo de forma satisfatória. Como os sinais combinados são de uso interno e não se concretizam como sinais-termo, sua plena divulgação não ocorre. Caso a criação de sinais tenha como finalidade a divulgação e a concretização de seu uso, a atenção deve ser redobrada com o auxílio de profissionais, de dicionários utilizados para a compreensão dos significados dos termos, com o respeito às normas gramaticais das línguas de sinais, a validação e o uso do neologismo nessa língua. É importante ter em mente também, que a convenção e a concretização de um sinal criado demandam tempo e uso, tal como acontece com as palavras criadas nas línguas orais, sejam essas dicionarizadas ou de senso comum.

Neste artigo, relataremos o processo de criação de quatro sinais, em 2014, para os termos: carboidrato, fibra, metabolismo e proteína, com as experiências e resultados obtidos, pois não encontramos registros de sinais para esses quatro termos, muito utilizados no ensino médio. O trabalho de pesquisa foi executado por uma docente surda, bilíngue, e por quatro 
alunas ouvintes da Universidade Federal de Goiás (UFG), de acordo com as seguintes etapas: a busca por significados para os termos, a tradução e interpretação dos significados para Libras, a escrita das línguas de sinais (ELiS), criada por Barros (1998), a elaboração de fichas terminológicas com base em Nascimento (2009), a criação de sinais pela docente surda, a validação dos sinais-termo, a filmagem e a divulgação dos sinais-termo.

A questão de pesquisa, a partir da qual este trabalho se desenvolveu, foi: como auxiliar o aluno surdo a suprir as necessidades de compreensão e apreensão do significado de termos em português, utilizados no cotidiano escolar, ausentes na Libras? Encontramos como resposta mais viável para essa questão a criação de sinais e sua consolidação, pela promoção de discussões com outros sujeitos sinalizantes sobre o termo. A parceria com a docente surda foi fundamental para o desenvolvimento da pesquisa, considerando-se que, por ser fluente e representante da comunidade surda, poderia criar sinais para os quatro termos escolhidos. Com esta pesquisa, procurou-se trazer contribuições ao léxico da Libras e revelar a dinâmica dessa língua. Com os novos sinais, buscou-se fornecer, imageticamente, significados ao Surdo e auxiliar o tradutor e intérprete, proporcionando-lhe uma atuação mais eficaz. O público alvo foi, principalmente, alunos surdos e TILSP do ensino médio, mas o que se espera é que sejam úteis para todos os falantes da Libras, estendendo-se aos profissionais da área da saúde que lidam com pessoas surdas.

Este trabalho tem por objetivo expor o processo utilizado na criação de quatro sinais da área de Nutrição, buscando situar o leitor quanto à iniciativa da escolha dos termos, sobre a metodologia utilizada na criação de cada sinal, relatando os resultados de cada etapa do processo, assim como as dificuldades encontradas e expondo os resultados preliminares póscriação destes sinais. Para tal, antes serão necessárias algumas considerações sobre a Libras e sua gramática.

\section{A gramaticalidade da Língua de Sinais}

Os sinais são o léxico das línguas de sinais, as quais apresentam, naturalmente, sua própria fonologia, morfologia, sintaxe e semântica. A fonologia das línguas de sinais, de acordo com Quadros e Karnopp (2004), visa identificar a estrutura dos sinais através de modelos descritivos e explanatórios, estabelecendo padrões possíveis de combinação entre as unidades mínimas que compõem um sinal. A fonologia estuda os parâmetros da Libras, 
propostos por William Stokoe (1960), que viabilizou três parâmetros: Configuração de Mão (CM), Movimento (M) e Locação (L), também conhecido como Ponto de Articulação (PA).

Alguns anos depois, Batisson (1974) acrescentou outra unidade mínima na Libras: Orientação da Palma das Mãos (O). Um quinto parâmetro foi incluído por Lidell \& Johnson (1989), os traços não-manuais, atualmente conhecidos como ENM. As CMs demonstram o formato das mãos na execução dos sinais, feitos com uma ou duas mãos. Na Libras há mais de 62 configurações de mãos e no alfabeto manual são utilizadas 26 para representar as letras (Brito, 1995). A figura 1 apresenta algumas das configurações existentes:

Figura 1 - Configurações de Mãos.

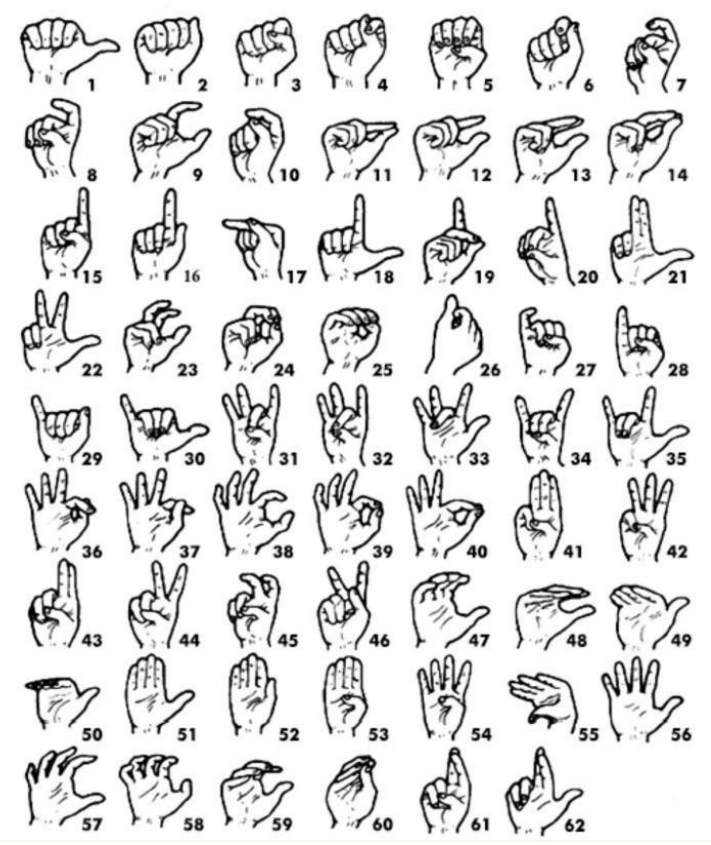

Fonte: http://coral.ufsm.br/edu.especial.pos/unidadeA_LibrasII.html. Acesso 02/05/2017.

O PA é o local onde a mão incide e são feitos os sinais, podendo ser em alguma parte do corpo ou num espaço neutro. Os MOs podem ser alterados quanto à direção, à maneira e à frequência, no entanto, há sinais que não apresentam movimento em sua composição, como por exemplo os sinais de DESCULPA e ADMIRAR. As ENM, além de essenciais na conversação em Língua de Sinais, podem interferir na própria gramática da língua, por exemplo, marcando o grau aumentativo ou diminutivo, grau de intensidade, entre outros. 
A morfologia da Libras se caracteriza pelo estudo da estrutura interna dos sinais. Quadros e Karnopp (2004) afirma que durante o processo de criação de sinais, as unidades mínimas de significado, os morfemas, formam sistemas combinatórios. Por semântica, entendemos o significado dos sinais transmitidos pelo usuário e a decorrente interpretação das sentenças. Por fim, tem-se na sintaxe da Libras, a organização espacial, que apresenta variedade na ordem das palavras podendo seguir várias estruturas no tocante a sujeito, verbo e objeto, como por exemplo: SVO, SOV ou VSO.

Sobre os requisitos para a criação de sinais, Biderman afirma que há uma única "possibilidade para um sistema lexical se cristalizar: a morte da língua. Foi o que aconteceu ao latim. Se a língua, porém, continuar a existir como meio de comunicação oral (e também escrito), seu léxico se ampliará sempre” (2001, p.203). Biderman toma por base as línguas orais, no entanto, é possível aplicar esse conceito à comunicação viso-gestual da Libras que, por sua vivacidade e dinamicidade, está sujeita a constantes modificações e ao surgimento de novos sinais.

Assim como ocorre na língua portuguesa, os surdos também fazem uso de neologismos no cotidiano, criando novos sinais. Há um consenso sobre o fato de que as pessoas com audição não deveriam criar sinais, somente os surdos, pois a língua de sinais é parte integrante de sua cultura. Quando tratamos de termos relativos a áreas específicas do conhecimento, os ouvintes podem se tornar sujeitos ativos nessa construção, auxiliando os Surdos com referências e explicações, para que eles possam compreender os significados dos termos. Os sinais relativos às áreas de conhecimento e linguagens específicas, geralmente são aprendidos conscientemente, dado o interesse ou necessidade, diferentemente dos sinais comuns, que são assimilados de forma natural, aleatoriamente, no cotidiano.

Para Biderman (1998), os termos científicos são gerados de acordo com os padrões lexicais e gramaticais das línguas envolvidas. Segundo Alves, assim como os termos em geral podem ser criados através de diferentes processos de formação de palavras, tais como “derivação, composição, truncação, transferência semântica, formação sintagmática e por siglas, empréstimos entre outros recursos das línguas” (1990, p. 104), a criação de sinais também segue os mecanismos que regem a configuração dessa língua. Os neologismos são produtos dessa criação, seja de termos técnico-científicos ou de palavras da língua em geral. De acordo com Barbosa, o neologismo: 
[...] tem uma função referencial, a função essencial da linguagem, a de comunicar uma informação nova. No ato de transmissão dessa informação estabelece-se uma relação informativa locutor-destinatário, graças à qual o receptor sofre uma modificação e adquire um conhecimento que não possuía (1981, p.80).

As produções científicas que têm como tema os léxicos de diferentes áreas do conhecimento em Libras apresentam considerável extensão e sugerem uma tentativa de padronizar regras para criação de novos sinais, considerando que seu processo de criação deve ser cuidadoso. Segundo Marinho, a natureza dos processos neológicos é variada, considerando-se que:

[...] alguns se baseiam em recursos fonológicos, como no caso das onomatopéias, outros, em morfossintáticos. Este último apoia-se essencialmente na derivação e na composição, de interesse da Morfologia. Os morfemas são elementos com significado que constituem as palavras. As possibilidades de combinação entre eles propiciam a formação de palavras e promovem a estreita ligação com a sintaxe (2007, p. 73).

A criação lexical nas línguas orais segue uma regra na formação das palavras, e nas línguas de sinais também não se criam sinais-termo de forma desordenada, ou ao menos, não se deveria fazê-lo. Felipe (2006) esclarece que os sinais são formados a partir de “composição, justaposição, aglutinação, incorporação, derivação e flexão", sendo preciso manter essa estrutura. A composição dos sinais, de acordo com Felipe (2006), é a junção de dois itens para formar um sinal a partir da justaposição, que pode ocorrer de três formas: a justaposição de dois itens lexicais que criam uma terceira forma livre (COMER + MEIO DIA = ALMOÇO); justaposição de um classificador com um item lexical (COISA-PEQUENA $(\mathrm{CL})$ + APLICAR-NO-BRAÇO = AGULHA); justaposição da datilologia em português e também com o sinal que representa a ação (COSTURAR-COM-AGULHA + A.G.U.L.H.A.).

A aglutinação, de acordo com Takahira (2012), ocorre quando um ou alguns dos sinais que formam um composto não são feitos em sua totalidade, ou seja, não são realizados ou são modificados. Sobre a incorporação, Quadros e Karnopp (2004) afirmam que ela se dá em algumas modalidades, tais como: pelo numeral, pela negação, pela incorporação da localização, pelos verbos direcionais, pelos sinais locativos, pelo formato do objeto e pela intensidade. A derivação é um processo que deriva nomes de verbos ou verbos de nomes, 
como em: sentar (v) e cadeira (s), carro (s) e dirigir (v). O que os diferencia é o contexto. A flexão dos sinais pode ser compreendida a partir das marcas do discurso, abrangendo a direcionalidade na fala, a flexão para termos verbais e definiçõos de gênero (pessoa, coisa, animal).

No que diz respeito às etapas da criação de sinais, é necessário que os profissionais da lexicologia e terminologia sejam atuantes em todo o processo junto ao lexicógrafo. Em caso afirmativo da ausência de sinal para determinado termo, ou até mesmo da existência de um sinal que não seja utilizado, é preciso estudar o significado do termo e torná-lo claramente compreendido através da contextualização em Libras, para que o novo sinal possa ser criado. O primeiro passo é uma busca minuciosa para constatar se não existe um sinal para o termo em nenhum dicionário ou glossário referencial da Língua de Sinais. Então, faz-se a soletração da palavra escolhida para uma pessoa Surda, que seja fluente na Língua de Sinais e tenha conhecimento de sua segunda língua, neste caso, a língua portuguesa. Para que o Surdo compreenda bem o significado do termo soletrado, são oferecidas informações e explicações baseadas em dicionários e em textos científicos. Isso deve ocorrer, especialmente, ao se tratar de termos de áreas técnico-científicas. Em nosso projeto, utilizamos repertórios lexicográficos específicos da área da Nutrição.

Para Werner (1982), os dicionários tradicionais de línguas orais permitem interpretar e utilizar corretamente os signos léxicos. Muitas vezes, pela necessidade emergente de um novo sinal, não são utilizados dicionários das áreas de conhecimento específico, os quais são mais relevantes na criação dos sinais, para que esses apresentem, morfologicamente, conceitos representativos e para que tornem possível a identificação imediata do significado do sinal, evitando ambiguidades. Segundo Alves (2009, p.47), consultar "glossários e dicionários especializados é, certamente, uma estratégia importante quando se desconhece uma terminologia específica".

Com posse da compreensão do significado da palavra e seguindo o processo que permeia as regras linguísticas da Libras, a pessoa surda cria o sinal em conjunto com outros surdos, tomando nota das considerações de um especialista da área a que o termo corresponda. Posteriormente, a divulgação se faz necessária, e também a verificação de aceite na comunidade que utiliza a língua de sinais (LS), que é o processo conhecido como validação dos sinais. Essa validação, tratando-se de sinais-termo de uma especialidade, é um 
processo lento, pois quando um sinal é criado conscientemente ele será validado conforme a necessidade de uso e, somente assim, os sinais serão colocados à prova. Após esta validação o novo sinal-termo é divulgado em produções impressas, sites referenciais, em mídias, nos cursos de formação e universidades, com intuito de atingir ao máximo o público que faz uso da Libras. Contudo, dado o processo de criação de sinais, há também algumas restrições, que podem ser de ordem fonológica, física, linguística e também cultural.

Quadros e Karnopp (2004) afirmam que o sistema visual e o sistema articulatório (fisiologia das mãos), podem influenciar na criação de neologismos e interferir na aceitação desses novos sinais. A maioria dos sinais é produzida na frente do corpo, pois assim se torna possível ao receptor identificar com mais facilidade pequenas diferenças de CM, PA ou MO, e poucos são os sinais produzidos com menor acuidade visual, ou seja, atrás do corpo ou em locais que dependem mais da visão periférica do que da visão central.

As restrições fonológicas requeridas para a boa-formação de sinais podem ser exemplificadas em sinais produzidos pelas duas mãos. De um modo geral, pode-se fazer a seguinte classificação: (a) sinais produzidos com uma mão; (b) sinais produzidos com as duas mãos em que ambas são ativas, e (c) sinais de duas mãos em que a mão dominante é ativa e a mão não-dominante serve como locação (QUADROS \& KARNOPP, 2004, p. 7).

Quadros e Karnopp (2004) citam os estudos de Battison (1978), os quais revelam nas restrições linguísticas duas condições: de simetria e de dominância, que podem ser violadas apenas pelos classificadores em Libras. A condição de simetria estabelece que se as duas mãos são ativas elas devem apresentar a mesma CM, o mesmo PA e devem ter o M simultâneo ou alternado, como ocorre com o sinal de TRABALHAR. Na condição de dominância, se as mãos apresentarem distintas CM, em que uma das mãos é a dominante e a outra é passiva, essa segunda deve servir de apoio para a mão dominante. Quadros e Karnopp (2004, p.79) citam como exemplo os sinais das palavras AJUDAR, APOIAR e CENTRO. Essas orientações foram cuidadosamente consideradas durante o processo de criação dos quatro sinais-termo da nossa proposta.

\section{Procedimentos metodológicos}

Esta pesquisa se caracteriza metodologicamente como qualitativa participativa, ou seja, aquela que, de acordo com Lima (2014), inclui o pesquisador como participante no 
objeto da pesquisa. Como citado anteriormente, a proposta de criação de sinais passou a ser discutida por quatro alunas do bacharelado quando uma delas, que trabalhava como intérprete no ensino médio, levantou algumas questões sobre a carência de sinais para os termos de áreas específicas, afirmando que suas maiores dificuldades ocorriam nas aulas de Biologia, pois muitas vezes precisava interromper a aula e pedir explicações para o docente. Os alunos surdos tinham muita dificuldade em expressar com clareza o que haviam compreendido, perdendo-se nas explicações e na datilologia, mas não apresentavam dificuldades com os termos que tinham sinais, por sua familiaridade com eles.

O trabalho de pesquisa foi dividido em três etapas: a) a recolha de termos; b) a definição de significados para os termos; c) a elaboração de uma estratégia de interpretação dos significados de cada termo para Libras. No primeiro momento, foi necessário que escolhêssemos, dentre os termos que não tinham sinais, aqueles mais recorrentes no contexto da nutrição. Através de uma conversa informal com TILSP e surdos do ensino médio, escolhemos quatro termos: carboidrato, fibra, metabolismo e proteína. Não objetivamos um repertório lexicográfico completo por se tratar de uma experiência nova e, por isso, nos limitamos a priorizar a busca pela qualidade e não a quantidade de verbetes.

No segundo momento, visto que já havíamos escolhido os termos, o objetivo foi encontrar uma definição adequada para cada um dos termos, utilizando repertórios lexicográficos da área de Nutrição. Procuramos em dicionários de Biologia e de Nutrição, mas não encontramos significados para todos os termos. Percebemos que os repertórios lexicográficos dessas áreas se assemelham mais a glossários ou manuais de alimentação, do que a dicionários.

Uma das dificuldades foi encontrar informações relevantes nos verbetes. De acordo com Welker (2004), são relevantes as informações que identificam o lema (entrada ou palavra-entrada), segundo a grafia, pronúncia, acentuação, classe gramatical e flexão. No site: http://pt.thefreedictionary.com/fibra, foram encontradas informações sobre a palavra "fibra", definida como "Elemento anatômico, longo e frágil". Contudo, esse significado não fez referência ao que realmente buscávamos, não tornando clara a função da fibra alimentar e conceituando-a de modo a torná-la compreensível no contexto da Nutrição. A maioria dos termos não tinham muitos dados na microestrutura do verbete, mas optamos por considerar os conceitos mais cabíveis de compreensão. Visávamos a criação de sinais que fossem acessíveis 
até mesmo para quem não fosse da área da saúde, especificamente da área de Nutrição. As informações insuficientes do verbete nos levaram a perceber a importância do uso de obras da área específica de conhecimento em questão, pois precisávamos compreender cada conceito, considerando as características, funções e reações no corpo humano de cada um dos elementos descritos.

Até chegarmos aos significados tivemos alguns entraves, como a presença da homonímia em alguns termos. Para Welker (2004, p.28) a homonímia ocorre quando um lexema apresenta "dois ou mais significados sem que haja nenhuma relação entre eles, ou seja, nenhum sema em comum (por exemplo, manga <de camisa>, manga $<$ fruta $>$ )". Sobre os homônimos, Welker observa que, ao se falar dessas ocorrências, pensa-se:

[...] em dois ou mais lexemas homógrafos (que se escrevem da mesma maneira). Mas a questão é se eles têm que: a) ser homófono (ter a mesma pronúncia), o que excluiria sede/sede ("tipo de sensação" / "tipo de lugar"); b) pertencer à mesma categoria gramatica, o que excluiria jantar (verbo) / jantar (substantivo); c) ter o mesmo gênero e/ou a mesma flexão, o que não é o caso de a cabeça / o cabeça, al. der Leiter / die Leiter, Banken /Bänke, Mütter/Muttern (2004, p. 28).

No caso do termo "fibra", encontramos homonímias nos dicionários de mecânica, no site: http://www.civilium.net/civil2000/dicionario.shtml. A palavra "fibra" aparece compondo a expressão "fibra de carbono", definida como um material "de altíssima resistência e pouco peso, composto de carbono e que já está sendo empregado na execução de barras ou tiras para serem incorporados no concreto para armação em peças", e também em "fibra ótica", referente a material "em forma de fios que é empregado na transmissão de dados e voz, aumentando inúmeras vezes a capacidade em relação aos meios usuais, sendo, porém de custo bem mais elevado".

As homonímias foram excluídas e os termos encontrados, mais compatíveis com a proposta, estão expostos no Quadro 1, com definições colhidas em uma publicação do Ministério da Educação, Secretaria de Educação Básica, intitulada Alimentação saudável e sustentável (http://portal.mec.gov.br/seb/arquivos/pdf/profunc/alimet_saud.pdf.), de Eliane Dutra et al (2007). 
Quadro 1 - Significados dos termos: carboidrato, fibra, metabolismo e proteína.

\begin{tabular}{|l|l|}
\hline \multicolumn{1}{|c|}{ TERMO } & \multicolumn{1}{|c|}{ SIGNIFICADO } \\
\hline $\begin{array}{l}\text { CARBOIDRATO } \\
\text { (açúcar) }\end{array}$ & $\begin{array}{l}\text { Possuem função principalmente energética. São utilizados pelos músculos } \\
\text { para realização de movimentos e são armazenados no fígado para } \\
\text { manutenção da glicemia. Quando em excesso, os carboidratos são } \\
\text { transformados em gorduras ou lipídios, a fim de economizar a energia } \\
\text { excedente para situações em que o corpo realmente necessitar dela. } \\
\text { Alterações no metabolismo da glicose podem ser indicativas de doenças } \\
\text { (DUTRA et al, 2007, p.19). }\end{array}$ \\
\hline FIBRA & $\begin{array}{l}\text { Representam um tipo especial de carboidratos que não fornece energia, mas } \\
\text { desempenha funções importantes em nosso organismo. As fibras } \\
\text { alimentares originam-se exclusivamente de plantas e possuem diferentes } \\
\text { propriedades físicas, químicas e fisiológicas. No corpo humano, elas } \\
\text { chegam intactas ao nosso intestino, ou seja, passam sem serem digeridas por } \\
\text { todo o processo digestório, e é no intestino que as fibras exercem sua } \\
\text { função essencial de formar as fezes e colaborar em sua eliminação. Existem } \\
\text { basicamente dois tipos de fibras, as solúveis e as insolúveis (DUTRA et al, } \\
\text { 2007, p.21-22). }\end{array}$ \\
\hline METABOLISMO & $\begin{array}{l}\text { É o conjunto de transformações que as substâncias químicas sofrem no } \\
\text { interior dos organismos vivos. Por exemplo, o nosso corpo metaboliza } \\
\text { nutrientes para obter energia (DUTRA et al, 2007, p.19). }\end{array}$ \\
\hline PROTEÍNA & $\begin{array}{l}\text { Proteínas: são nutrientes necessários para a formação de células e tecidos. } \\
\text { São as proteínas que permitem o crescimento e desenvolvimento do corpo, } \\
\text { e estão presentes nos músculos, ossos, cabelos, sangue, pele, entre outros. } \\
\text { Assim como os tijolos desempenham a função estrutural de um prédio, as } \\
\text { proteínas possuem, comparativamente, a mesma função no organismo } \\
\text { humano (DUTRA et al, 2007, p.20). }\end{array}$ \\
\hline
\end{tabular}

Ao final da primeira etapa, os significados obtidos para cada termo foram interpretados em Libras, com o objetivo de explicá-los para a docente, responsável pela criação dos sinais, para que ela pudesse compreendê-los com clareza. Algumas fichas escritas em português foram usadas para a explicação dos termos, ainda sem a representação de um sinal. Cada termo foi representado por letras maiúsculas e hífens (F-I-B-R-A), algumas preposições não foram usadas, os verbos permaneceram no infinitivo e alguns acréscimos, considerados relevantes, foram adicionados.

Quadro 2 - Estratégia para apresentação dos termos em Libras.

\begin{tabular}{|c|l|}
\hline \multicolumn{1}{|c|}{ TERMO } & \multicolumn{1}{c|}{ TEXTO COM GLOSAS } \\
\hline CARBOIDRATO & C-A-R-B-O-I-D-R-A-T-O o quê? Pão, massas, farinha branca, doces, açúcar. \\
& $\begin{array}{l}\text { Esses dar energia ao corpo. Se excesso (comer muito), C-A-R-B-O-I-D-R-A- } \\
\text { T-O pode trocar ter gordura, porque corpo guarda se futuro precisa energia. }\end{array}$ \\
\hline
\end{tabular}




\begin{tabular}{|l|l|}
\hline FIBRA & $\begin{array}{l}\text { Muito importante corpo humano. F-I-B-R-A alimento o quê? Frutas, verduras } \\
\text { e legumes principal. Se comer F-I-B-R-A descer intestino lá intestino } \\
\text { acontece troca, ajuda ter fezes. Também ajuda eliminar fezes. }\end{array}$ \\
\hline METABOLISMO & $\begin{array}{l}\text { Corpo recebe alimentos, acontece energia, mudança dentro nome M-E-T-A- } \\
\text { B-O-L-I-S-M-O o quê? Transformação (trocas) dentro corpo humano. Às } \\
\text { vezes pode mais rápido acelerado, ou mais lento. Se muito lento, por } \\
\text { exemplo, pode acontecer sono, preguiça, desânimo também obesidade. }\end{array}$ \\
\hline PROTEÍNA & $\begin{array}{l}\text { P-R-O-T-E-Í-N-A o quê? Ter alimentos exemplo: carne, ovo, leite, queijos, } \\
\text { cereais. Muito importante P-R-O-T-E-Í-N-A dentro célula e corpo humano. } \\
\text { P-R-O-T-E-Í-N-A, ajuda crescer, desenvolver corpo. Ter P-R-O-T-E-Í-N-A } \\
\text { dentro músculos, ossos, cabelos, sangue, pele, outros também. }\end{array}$ \\
\hline
\end{tabular}

Interpretamos os conceitos, apresentando o significado original em língua portuguesa, juntamente com vídeos que mostravam a composição dos termos, e a docente não teve dificuldades. Ao compreender os significados de cada termo, ela os utilizou em algumas frases. Como também não tivemos dificuldades em compreendê-la, percebemos que havíamos obtido sucesso.

\section{A criação dos sinais-termo}

Essa fase do processo, que corresponde à criação dos sinais para os quatro termos escolhidos, se divide em quatro etapas: criação dos sinais; criação das fichas e escrita em ELiS; validação dos sinais-termo; filmagem e divulgação dos sinais-termo. Na etapa da criação de sinais, a docente surda conversou com outros surdos, docentes em universidades, que conheciam os termos. Após a consulta, ela pensou em criar os sinais a partir de uma morfologia mais imagética e, ao fazê-lo, voltou a consultar os colegas surdos, por meio de vídeos onde explicava suas opções no processo de criação dos sinais.

A etapa seguinte foi de elaboração de fichas terminológicas que pudessem exemplificar a microestrutura dos sinais-termo, o que nos auxiliaria na terceira etapa, a de validação. Com base em Nascimento (2009), tentamos fazer as descrições, mas como não tínhamos todos os dados necessários, decidimos expor nas fichas informações a definição em português dos sinais-termo; escrita do sinal em ELiS; imagem do sinal-termo; link para acesso ao vídeo do sinal (que foi inserido posteriormente nas fichas); definição em português; adaptação do conceito para a Libras e a descrição dos parâmetros fonológicos do sinal.

No verbete "carboidrato" a energia dada por um alimento é representada pela mão passiva. A mão ativa tenciona mostrar o corpo sugando o carboidrato do alimento ingerido. 
Quadro 3 - Ficha terminológica do sinal-termo CARBOIDRATO

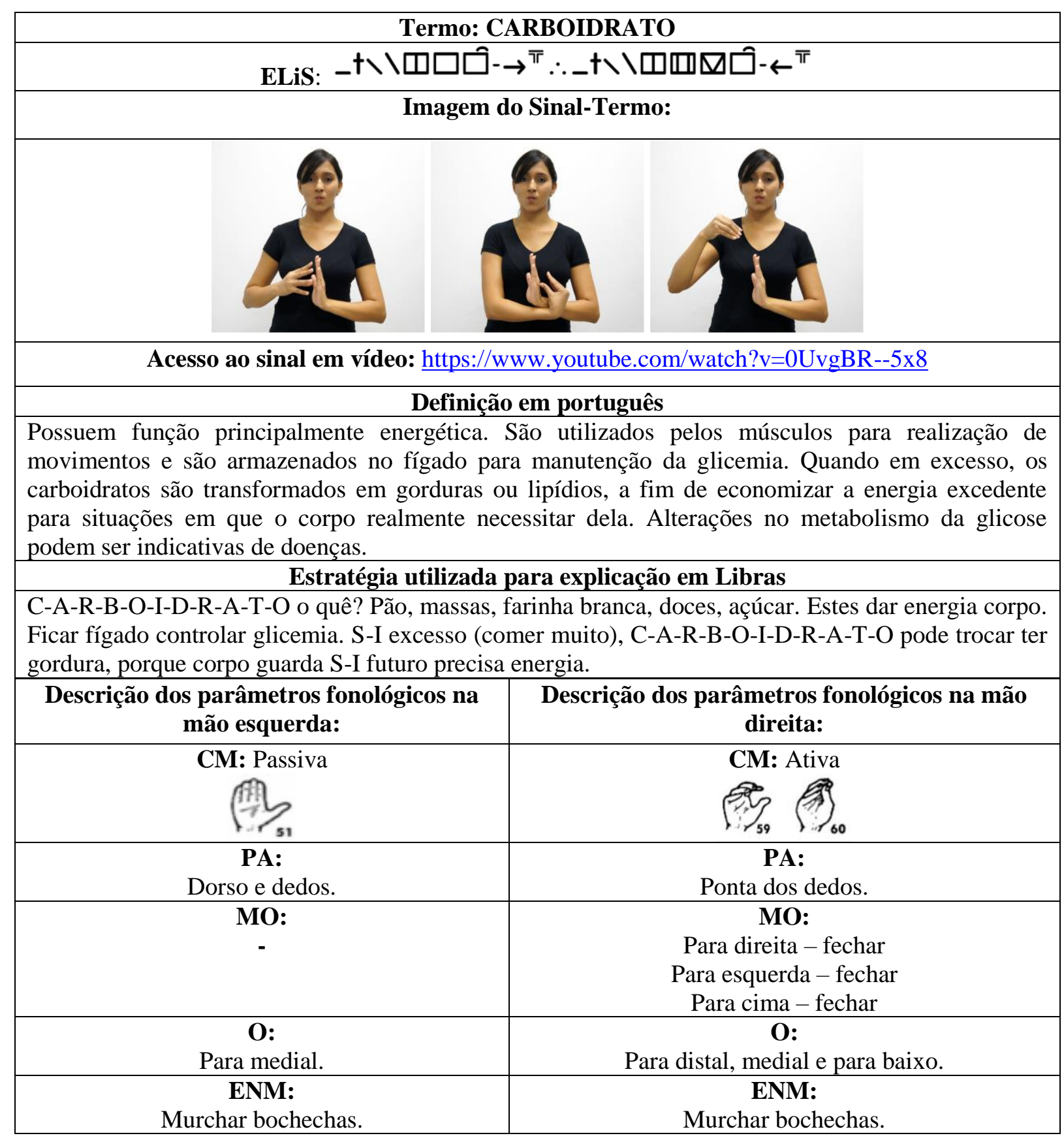

O sinal "fibra" (Quadro 4) sugere fluidez pelo movimento da mão ativa, como se provocasse a expulsão de algo do corpo. 
Quadro 4 - Ficha terminológica do sinal-termo FIBRA

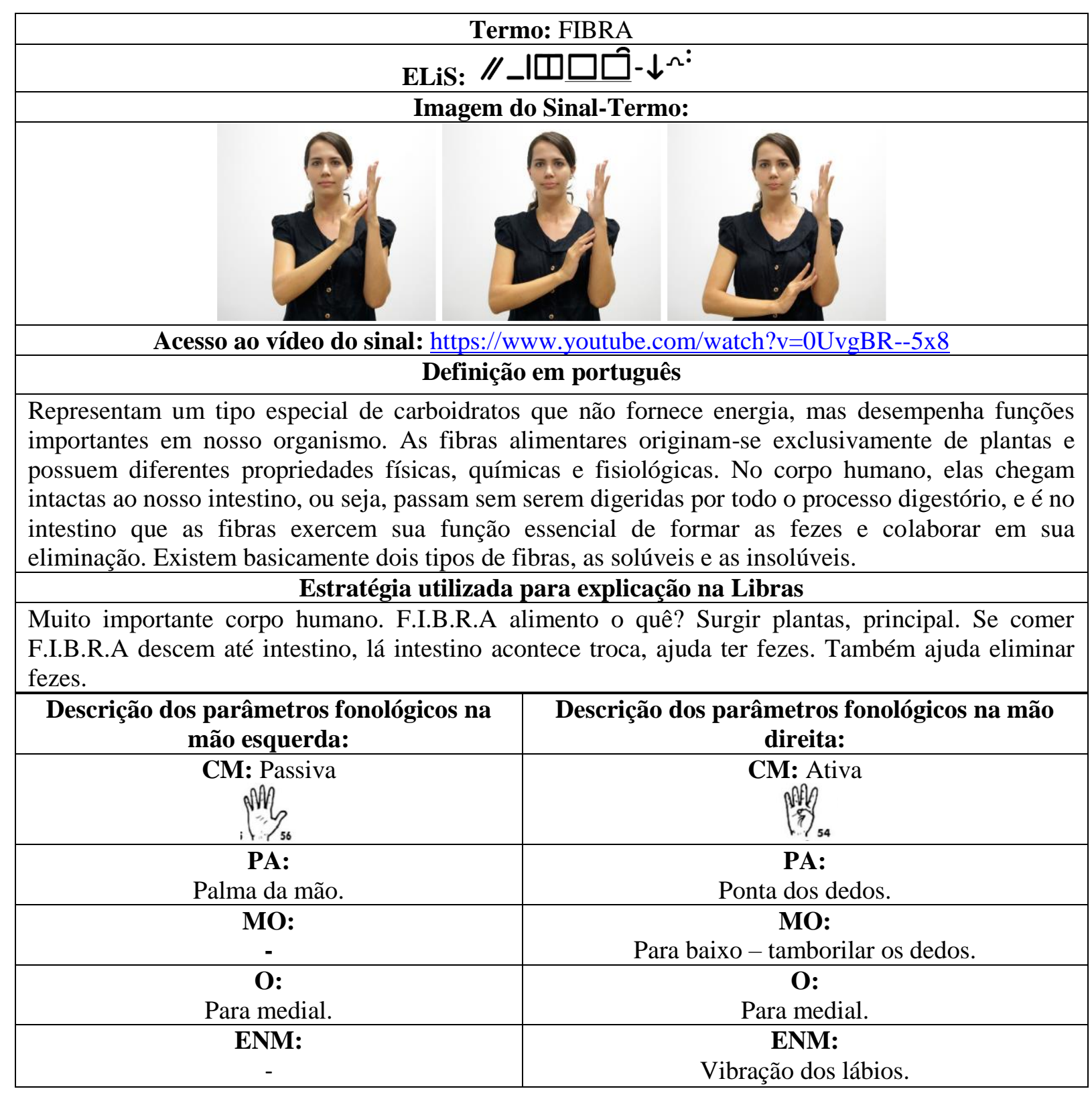

O sinal "metabolismo" (Quadro 5), representa, em sua forma, as células em movimento. Se feito de forma lenta, indica um metabolismo lento, e com movimento mais rápido, um metabolismo acelerado. 
Quadro 5 - Ficha terminológica do sinal-termo METABOLISMO

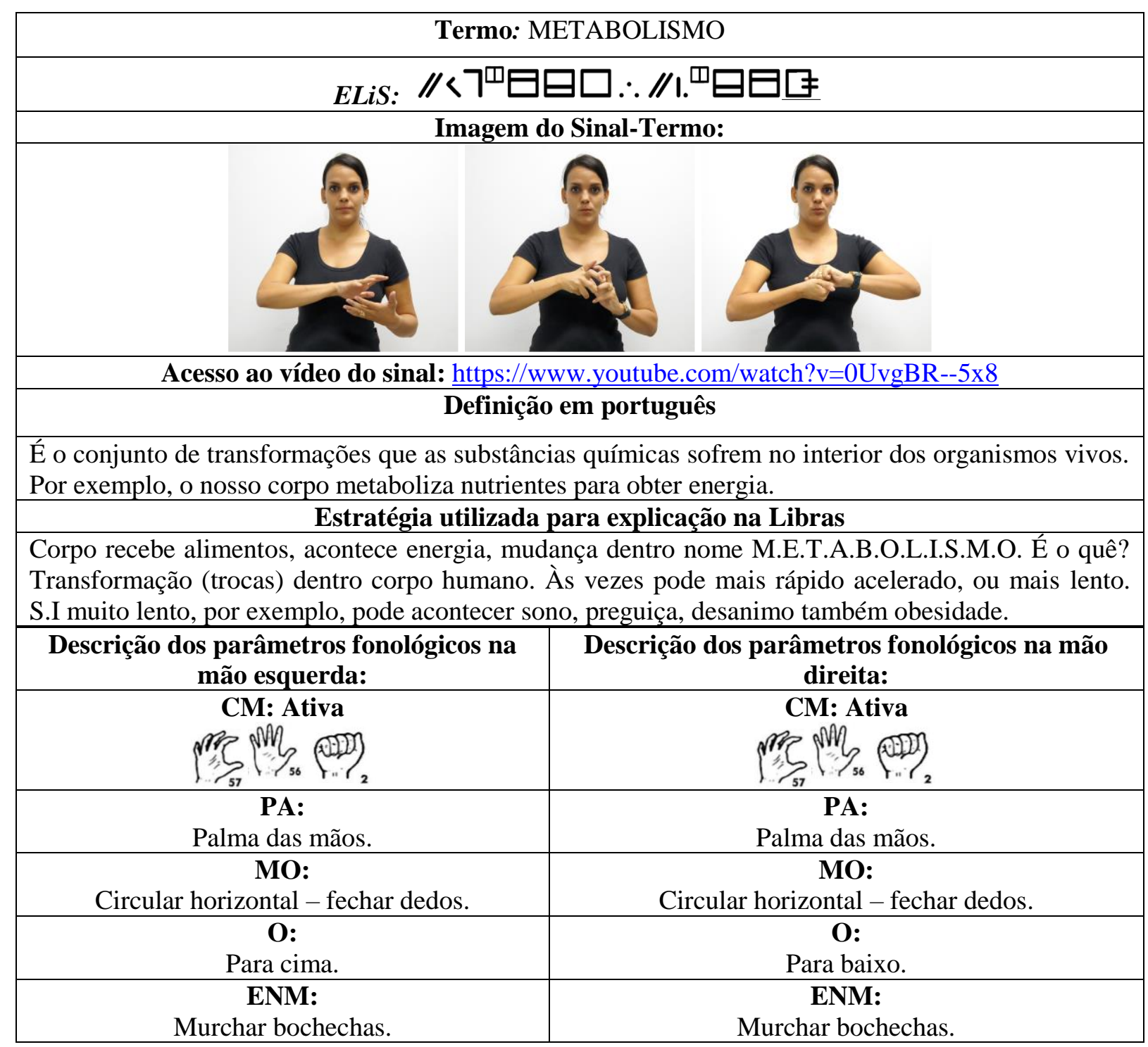

O sinal de "proteína" (Quadro 6), indica o crescimento muscular, função também, de alimentos proteicos. 
Quadro 6 - Ficha terminológica do sinal-termo PROTEÍNA

\begin{tabular}{|c|c|}
\hline \multirow{2}{*}{\multicolumn{2}{|c|}{ 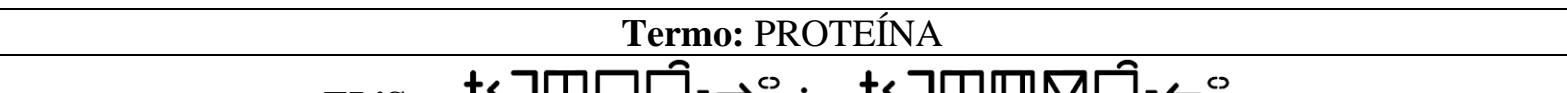 }} \\
\hline & \\
\hline \multirow{2}{*}{\multicolumn{2}{|c|}{ Imagem do Sinal-Termo: }} \\
\hline & \\
\hline \multicolumn{2}{|c|}{ Acesso ao vídeo do sinal } \\
\hline \multicolumn{2}{|c|}{ https://www.youtube.com/watch?v=0UvgBR--5x8 } \\
\hline \multicolumn{2}{|c|}{ Definição em português } \\
\hline \multirow{2}{*}{\multicolumn{2}{|c|}{$\begin{array}{l}\text { Proteínas: são nutrientes necessários para a formação de células e tecidos. São as proteínas que } \\
\text { permitem o crescimento e desenvolvimento do corpo, e estão presentes nos músculos, ossos, cabelos, } \\
\text { sangue, pele, entre outros. Assim como os tijolos desempenham a função estrutural de um prédio, as } \\
\text { proteínas possuem, comparativamente, a mesma função no organismo humano. } \\
\text { Estratégia utilizada para explicação na Libras }\end{array}$}} \\
\hline & \\
\hline \multicolumn{2}{|c|}{$\begin{array}{l}\text { P.R.O.T.E.Í.N.A o quê? Tem alimentos exemplo: carne, ovo, leite, queijos, cereais. Muito importante } \\
\text { P.R.O.T.E.Í.N.A dentro célula e corpo humano. P.R.O.T.E.Í.N.A, ajuda crescer, desenvolver corpo. } \\
\text { Ter P.R.O.T.E.Í.N.A dentro músculos, ossos, cabelos, sangue, pele, outros também. }\end{array}$} \\
\hline $\begin{array}{c}\text { Descrição dos parâmetros fonológicos na } \\
\text { mão esquerda: }\end{array}$ & $\begin{array}{l}\text { Descrição dos parâmetros fonológicos na mão } \\
\text { direita: }\end{array}$ \\
\hline CM: Passiva & CM: Ativa \\
\hline $\begin{array}{c}\text { PA: } \\
\text { Palma e dorso. }\end{array}$ & $\begin{array}{c}\text { PA: } \\
\text { Ponta dos dedos. }\end{array}$ \\
\hline $\begin{array}{c}\text { MO: } \\
-\end{array}$ & $\begin{array}{c}\text { MO: } \\
\text { Abrir para laterais - unir e separar dedos. }\end{array}$ \\
\hline $\begin{array}{c}\text { O: } \\
\text { Para medial. }\end{array}$ & $\begin{array}{l}\text { O: } \\
\text { Para medial e depois distal. }\end{array}$ \\
\hline $\begin{array}{c}\text { ENM: } \\
\text { Inflar bochechas }\end{array}$ & $\begin{array}{c}\text { ENM: } \\
\text { Inflar bochechas }\end{array}$ \\
\hline
\end{tabular}

O terceiro momento do processo corresponde à validação dos quatro sinais-termo. Para essa etapa contou-se com a participação de Surdos e TILSP de vários estados, mas principalmente do estado de Goiás. Inicialmente, houve maior divulgação na cidade de Goiânia, em algumas instituições de ensino de Libras e na UFG. Os sinais foram divulgados através de conversas informais, aplicativos em celulares e reuniões com TILSP, oferecidas pela Secretaria Estadual de Educação. No período de seis meses percebemos uma boa 
aceitação da comunidade sinalizante, o que nos levou a filmar os sinais e divulgá-los em âmbito nacional. Os sinais foram publicados no You Tube e, atualmente, contam com 1.472 visualizações.

O quarto momento foi de divulgação dos quatro sinais-termo. A primeira, para um número maior de pessoas, aconteceu em 2014, no $4^{\circ}$ Congresso Nacional de Pesquisas em Tradução e Interpretação de Libras e Língua Portuguesa, na Universidade Federal de Santa Catarina (UFSC), na cidade de Florianópolis. Ao apresentar os quatro sinais, percebemos a aprovação da comunidade de Surdos e TILSP.

\section{Conclusão}

Sabemos que a criação de sinais é algo polêmico entre os sinalizantes. Atualmente as técnicas estão mais desenvolvidas e o aporte teórico, mais fortalecido. Um contexto diferente do que tivemos na época da criação dos quatro sinais aqui expostos. Entretanto, ao confirmarmos que os sinais estavam sendo utilizados nas aulas de Biologia, percebemos que o objetivo de auxiliar o TILSP e o aluno surdo em período escolar na compreensão dos sinaistermo foi concretizado. O número reduzido de verbetes foi útil como um teste inicial e também para que aprendêssemos com os erros.

Outras ações importantes foram: inserir frases com os sinais criados, mostrando o seu contexto de uso; elaborar uma divulgação mais profissional, com um pouco mais de formalidade e ter na equipe um surdo lexicógrafo. Percebemos uma boa aceitação dos surdos e também uma boa receptividade dos TILSP, ao conhecerem os sinais. Aos que recebiam a sinalização, após conhecer o significado, identificamos que compreendiam com mais facilidade numa segunda visualização, sem questionar nem interromper a fala do professor. Os que visualizavam os sinais os utilizavam depois, com propriedade, em contextos frasais, transmitindo o conceito corretamente. A apresentação dos sinais está disponível no youtube, em: https://www.youtube.com/watch?v=0UvgBR--5x8 em publicação intitulada: Dicionário: Vida Saudável.

Atualmente, identificamos algumas variações de sinais para os quatro termos aqui citados, no entanto, não obtivemos informações sobre a predominância de algum desses sinais sobre os criados neste trabalho, principalmente por se tratar de termos específicos, que não circulam de modo cotidiano. Essas variações comprovam a necessidade dos sinalizantes 
suprirem a carência de sinais e de se divulgar de forma mais ativa os sinais-termo já existentes. Por outro lado, também expõem a vivacidade que permeia as Línguas de Sinais e os avanços que, felizmente, continuam a ocorrer nessa área ${ }^{1}$.

\begin{abstract}
The absence of signs in specific areas brings some problems for users and professionals who work with the Brazilian Sign Language (Libras). Excessive use of datilology, interruptions in translation / interpretation, and inadequacy of meanings are some of these problems. This article is the result of a project that aimed at the creation of a glossary for Nutrition, with the elaboration of signs for the terms: Carbohydrate, Fiber, Metabolism and Protein, with the participation of a deaf teacher and students of Translation and Interpretation Course in Libras/ Portuguese of the Federal University of Goiás (UFG), Goiânia. The purpose of this article is to describe the research, reporting the reasons for this initiative, the steps to reach the proposed objective, the failures which occurred, and the validation and current use of these signals.
\end{abstract}

Keywords: Signal creation. LSB. Neologism. Nutrition. Terminology.

\title{
Resumen
}

La ausencia de señales en áreas específicas trae algunos problemas para usuarios y profesionales que actúan con la Lengua Brasileña de Señales (LIBRAS). El uso excesivo de la detilología, interrupciones en la traducción / interpretación e inadecuación de significados son algunos de esos problemas. Este artículo es resultado de un proyecto que tuvo el objetivo de elaborar un glosario para el área de Nutrición, con la elaboración de señales para los términos: Carbohidrato, Fibra, Metabolismo y Proteína, contando con la participación de una docente sorda y alumnas del Curso de Letras: Traducción e Interpretación en LIBRAS / Portugués de la Universidad Federal de Goiás (UFG), Goiânia. El objetivo de este artículo es describir la investigación, relatando las razones de esa iniciativa, las etapas para lograr el objetivo propuesto y las fallas ocurridas, además de la validación y el uso actual de esas señales.

Palabras clave: Creación de señales, LSB, Neologismo, Nutrición, Terminología.

\section{REFERÊNCIAS}

ALVES, I. M. Neologismo: criação lexical. Série Princípios. São Paulo: Ática, 1990. Formação e Classes de Palavras no Português do Brasil. São Paulo: Contexto, 2009. 
BARBOSA, M. A. Léxico, produção e criatividade: processos do neologismo. São Paulo: Global, 1981.

BARROS, M. E. ELiS: sistema brasileiro de escrita das ínguas de sinais. Porto Alegre: Penso, 2015. 1998.

BATTISON, R... "Phonological deletion in American Sign Language". In: Sign Language Studies, v. 5, p.1-19, 1974.

BIDERMAN, M. T. C. Dimensões da palavra. Filologia e Linguística Portuguesa, n. 2, p. 81- 118, 1998.

DUTRA, Eliane Said [et al.]. Alimentação saudável e sustentável. Brasília: Universidade de Brasília, 2007. Disponível em: http://portal.mec.gov.br/seb/arquivos/pdf/profunc/alimet_saud.pdf. Acesso em: 20 jul 2016.

BEZERRA, LG; CARDOSO, V. R; CAMARGO, A. A; OLIVEIRA, J. C. Dicionário específico: vocabulário saudável. Trabalho apresentado no IV Congresso Nacional de Pesquisas em Tradução e Interpretação de Libras e Língua Portuguesa. Disponível em: http://www.congressotils.com.br/anais/anais2014.html. Acesso em: 20 jul 2016.

BIDERMAN, Maria Tereza Camargo. Teoria linguística: teoria lexical e linguística computacional. 2. ed. São Paulo: Martins Fontes, 2001.

FAULSTICH, E. Glossário de termos empregados nos estudos da Terminologia, da Lexicografia e da lexicologia. Inédito, Centro de Estudos Lexicais e Terminológicos (Centro Lexterm). Brasília: UnB, 2011.

E. Sinal-Termo. Nota lexical. Centro de Estudos Lexicais e Terminológicos (Centro Lexterm). Brasília: UnB, 2014.

FELIPE, Tanya Amara. Os processos de formação de palavra na Libras. ETD - Educação Temática Digital v. 7, n. 2, p. 200-217, 2006.

BRITO, L. F.. Por uma gramática de línguas de sinais. Rio de Janeiro: Tempo Brasileiro: UFRJ, Departamento de Lingüística e Filologia, 1995.

LIDDELL, S. K.; JOHNSON, R.E.. "American Sign Language: The Phonological Base”. In: Sign Language Studies, V. 64. Jan. 1989. Disponível em:

https://www.researchgate.net/publication/242530098_American_Sign_Language_The_Phono logical_Base Acesso em: 10 abr. 2018.

LIMA, V. L. S. Língua de Sinais: proposta terminológica para a área de desenho arquitetônico. Tese de Doutorado em Linguística aplicada. Universidade Federal de Minas Gerais, Belo Horizonte, 2014. 
MARINHO, M, L. O ensino da Biologia: o intérprete e a geração de sinais. Dissertação de Mestrado, Brasília, 2007.

NASCIMENTO, S. P. F. Representações lexicais da Língua de Sinais Brasileira: uma proposta lexicográfica. Tese de Doutorado em Linguística. Universidade de Brasília, Brasília, 2009.

QUADROS. R. M.; KARNOPP L. B. Língua de Sinais Brasileira: estudos linguísticos. Porto Alegre: Artmed, 2004.

STOKOE, William. "Sign Language Structure: an outline of the visual communication System of the American Deaf Studies" In: Linguistics, Buffalo 14, New York, v. 1, n. 8, p.3-78, abr. 1960.

The free dictionary by farlex. Disponível em: http://pt.thefreedictionary.com/fibra. Acesso em 28 ago. 2014.

TAKAHIRA, A. G. R.. "Questões sobre compostos e morfologia da LIBRAS". Universidade de São Paulo (USP). Estudos Linguísticos, p. 262-276, jan-abr, 2012.

UFG. Dicionário: Vida Saudável. Disponível em:

https://www.youtube.com/watch?v=0UvgBR--5x8 . Acesso em: 10 abr.2018.

WELKER, H. A. Dicionários: uma pequena introdução à lexicografia. Brasília: Theasaurs, 2004.

WERNER, R. La definición lexicográfica. In: HAENSCH, G. et al. Lexicografia: de la linguística teórica a la lexicografica practica (la). Madrid: Gredos, 1982.

\section{Nota}

${ }^{1}$ Este projeto foi apresentado no $4^{\circ}$ Congresso Nacional de Pesquisas em Tradução e Interpretação de Libras e Língua Portuguesa na UFSC (Universidade Federal de Santa Catarina) na modalidade de banner. Disponível em: http://www.congressotils.com.br/anais/2014/2952.pdf. 